\title{
A New Al-Zr-Ti Master Alloy for Ultrasonic Grain Refinement of Wrought and Foundry Aluminum Alloys
}

\author{
V.M. SREEKUMAR ${ }^{1,3,4}$ and D.G. ESKIN ${ }^{1,2,5}$ \\ 1.-Brunel University London, BCAST, Uxbridge UB8 3PH, UK. 2.-Tomsk State University, \\ Tomsk, Russia 634050. 3.-e-mail: vm.srees@gmail.com. 4.—e-mail: Sreekumar.VadakkeMadam@ \\ brunel.ac.uk. 5.—e-mail: Dmitry.Eskin@brunel.ac.uk
}

\begin{abstract}
A new grain refiner master alloy based on the Al-Zr-Ti system was prepared by salt-assisted synthesis. Of the $\mathrm{Al}_{3} \mathrm{Zr}$ particles in the master alloy, $90 \%$ were ranged between $1 \mu \mathrm{m}$ and $13 \mu \mathrm{m}$. An $80 \%$ reduction in the grain size was observed with the addition of an equivalent $0.2 \mathrm{wt} . \% \mathrm{Zr}$ master alloy combined with ultrasonic treatment in an $\mathrm{Al}$ alloy. The new master alloy demonstrated a $30 \%$ improvement in grain refinement efficiency as compared to the master alloy prepared from conventional binary master alloys.
\end{abstract}

\section{INTRODUCTION}

Grain refinement is an important practice assuring the quality of metal castings, e.g., by reducing casting defects and improving the properties for downstream processing. There are several techniques available to induce grain refinement: physical methods (mechanical shearing and ultrasonic cavitation); and chemical methods (inoculation and growth restriction). The most common practice is inoculation of the aluminum with $\mathrm{TiB}_{2}$ particles introduced in the form of Al-Ti-B master alloys. Excessive $\mathrm{Ti}$ within the master alloys acts as a growth restriction element in addition to activating $\mathrm{TiB}_{2}$ substrates. ${ }^{1,2}$ For industrial use, Al-Ti-B master alloys are added as rods or waffles to melt in the furnace or launder prior to casting. One major drawback of Al-Ti-B master alloys is the agglomeration of $\mathrm{TiB}_{2}$ particles in the melt during master alloy addition, which may affect the quality of the cast metal and create defects in the casting. Another is the limited efficiency in high-Si alloys due to the "poisoning" of $\mathrm{TiB}_{2}{ }^{2}$ Direct alloying with highgrowth restriction elements such as $\mathrm{Ti}$ and $\mathrm{V}$ provides grain refinement in $\mathrm{Al}$ but this requires high addition rates $(0.15-0.35 \mathrm{wt} . \%)$ and is therefore expensive. Several studies have identified intermetallic compounds such as $\mathrm{Al}_{3} \mathrm{Ti}, \mathrm{Al}_{3} \mathrm{Nb}$, and $\mathrm{Al}_{3} \mathrm{Sc}$ in aluminum alloys that may act as efficient nucleation sites during solidification. ${ }^{1,3,4}$

Ultrasonic cavitation is reported as an efficient method for grain refinement. ${ }^{5,6}$ In particular, ultrasonication (US) of molten $\mathrm{Al}$ alloys was found to reduce the size and change the morphology of the intermetallics that usually form above the solidification temperature of aluminum. ${ }^{7}$ Grain refining in $\mathrm{Al}$ alloys containing $\mathrm{Zr}$ that has been subjected to US was reported in the $1960 \mathrm{~s}^{8}$ but without proper analysis of the mechanisms. Considerable grain refinement was achieved in $\mathrm{Zr}$ and $\mathrm{Ti}$ containing pure $\mathrm{Al}, \mathrm{Al}-\mathrm{Cu}$ alloys, and in a number of commercial alloys when ultrasonic cavitation was applied in the temperature range of primary solidification of intermetallics. ${ }^{7,9}$ It was suggested that the refinement of large (tens of $\mu \mathrm{m}$ ) primary $\mathrm{Al}_{3} \mathrm{Zr}$ intermetallic particles to a size of a few $\mu \mathrm{m}$ and their dispersion make them suitable for becoming heterogeneous nucleation sites for the aluminum. ${ }^{7,9}$ It was also found that the $\mathrm{Al}_{3} \mathrm{Zr}$ phase readily nucleates on alumina inclusions. ${ }^{10}$ In this case, the ultrasonication facilitates this process by wetting and dispersing the naturally occurring oxides. Hence, several mechanisms of primary intermetallic refinement under US processing could operate, e.g., enhanced nucleation on dispersed oxides and fragmentation of crystals. The grain refinement of $\mathrm{Al}$ alloys with primary intermetallics and ultrasonic cavitation can be attractive to the industry because it (1) eliminates the necessity of AlTiB additions (some high-strength alloys actually already contain additions of $\mathrm{Zr}$ and Ti as a part of the alloy formula), and (2) turns potentially harmful coarse primary intermetallics into useful substrates for the nucleation of the aluminum.

This paper investigates the grain refining efficiency of an Al-Zr-Ti intermetallic feedstock alloy manufactured by salt-assisted synthesis. This alloy 
is used as a grain refining master alloy in combination with ultrasonic cavitation for two $\mathrm{Al}$ alloys representative of wrought and foundry alloys.

\section{EXPERIMENTAL}

A master alloy with a nominal composition Al5 wt.\% $\mathrm{Zr}-1.25$ wt.\% $\mathrm{Ti}^{*}$ (MA2) was prepared by reacting liquid $\mathrm{Al}$ with a $\mathrm{K}_{2} \mathrm{TiF}_{6}-\mathrm{K}_{2} \mathrm{ZrF}_{6}$ salt mixture. The salts were mixed manually to assure that the $\mathrm{Zr}$ :Ti ratio was 4:1 in the final composition. An amount of $1 \mathrm{~kg}$ of commercial pure $\mathrm{Al}$ (CPAl) (99.7\% purity $\mathrm{Al}$ ) was melted in a clay graphite crucible at a temperature of $800^{\circ} \mathrm{C}$ and the salt powder was mixed using a graphite rod. The reaction and subsequent increase in the temperature due to the exothermic nature of the reaction was monitored using a K-type thermocouple. The melt was allowed to react with the salt for 30-60 min with intermittent stirring and then cast in a 10-mm-diameter metallic mold. The cast billets were subsequently hot-rolled at $400^{\circ} \mathrm{C}$ to a 6 -mm-diameter rod using a rolling machine.

A reference master alloy with a nominal composition $\mathrm{Al}-2$ wt.\% $\mathrm{Zr}-0.5$ wt.\% Ti (MA1) was prepared from commercial binary master alloys (Al-6\% $\mathrm{Zr}$ and $\mathrm{Al}-5 \% \mathrm{Ti}$ ). It was not possible to make a more concentrated master alloy using the commercially available binary master alloys. Note that the same 4:1 ratio between the $\mathrm{Zr}$ and $\mathrm{Ti}$ concentrations was maintained. The alloy was also cast and rolled as described above.

In order to check the master alloy compositions, the master alloys were diluted with CPAl to approximately 0.2 wt.\% $\mathrm{Zr}$ (within the detectable limits of optical spectroscopy) and the resultant composition was measured using optical emission spectroscopy (Foundry Master). The experiments were repeated several times to approximate the composition of the alloys, which proved to be quite close (within 0.1 wt.\%) to the nominal formulation.

Grain refinement experiments were conducted on Al-3 wt.\% $\mathrm{Cu}$ and $\mathrm{A} 357$ (7.4 wt.\% Si, 0.5 wt.\% Mg, 0.1 wt.\% $\mathrm{Fe}, 0.1$ wt.\% Ti, remaining $\mathrm{Al}$ ) alloys. An amount of $500 \mathrm{~g}$ of each alloy was melted at $760^{\circ} \mathrm{C}$ in a clay graphite crucible. A master alloy was added manually at $760^{\circ} \mathrm{C}$ in the amount equivalent to 0.2 wt.\% $\mathrm{Zr}$ and was allowed to dissolve for 10 min with subsequent stirring of the melt. Ultrasonication (water-cooled magnetostrictive system (Reltec), $17.5 \mathrm{kHz}, 3.5 \mathrm{~kW}, 40 \mu \mathrm{m}$ peak to peak amplitude, $\mathrm{Nb}$ sonotrode dipped $1 \mathrm{~cm}$ below the melt surface) was performed after the addition of the master alloy in the temperature range 760 $700^{\circ} \mathrm{C}$. The processing time was about $30 \mathrm{~s}$. All alloys were cast at $700^{\circ} \mathrm{C}$ in a metallic mold preheated at $250^{\circ} \mathrm{C}$. Sound billets without obvious casting defects were produced in all cases.

*The 4:1 ratio between $\mathrm{Zr}$ and Ti follows previously published work. $^{9}$
The cast samples were ground using $\mathrm{SiC}$ paper (400-2500 grit size) and polished using OPS. To determine and measure grain size, the polished samples were anodised using a $4 \% \mathrm{HBF}_{4}$ solution for approximately $1 \mathrm{~min}$ at $20 \mathrm{VDC}$ and analysed in cross-polarized light with a filter in an optical microscope (Zeiss Axioscope).

\section{RESULTS}

Figure 1 shows the cast (a), machined (b) and rolled (c) billets of MA2. The optical microstructure of MA1 (Fig. 2a and b) revealed large elongated $\mathrm{Al}_{3} \mathrm{Zr}$ particles whereas MA2 (Fig. 2c and d) showed fine $\mathrm{Al}_{3} \mathrm{Zr}$ particles evenly distributed in the matrix. Rolling resulted in the fracture of the large intermetallic particles in MA1 but did not significantly affect the size and distribution of intermetallics in MA2. Figure 3 shows that the $\mathrm{Al}_{3} \mathrm{Zr}$ particles in MA2 range in size from $1 \mu \mathrm{m}$ to $30 \mu \mathrm{m}$ and that $90 \%$ of the particle sizes are between $1 \mu \mathrm{m}$ and $13 \mu \mathrm{m}$. Note that only $\mathrm{Al}_{3} \mathrm{Zr}$ (with dissolved $\mathrm{Ti}$ ) was found in the structure of master alloys.

The grain refinement efficiency of MA2 and MA1 was tested on Al-3 wt.\% $\mathrm{Cu}$ and A357 alloys (Fig. 4). With the equivalent addition of 0.2 wt. $\% \mathrm{Zr}$ master alloy to the $\mathrm{Al}-\mathrm{Cu}$ alloy, the initial grain size $(390 \mu \mathrm{m} \pm 53 \mu \mathrm{m})$ was reduced to $320 \mu \mathrm{m} \pm 30 \mu \mathrm{m}$ by US, to $170 \mu \mathrm{m} \pm 24 \mu \mathrm{m}$ by addition of MA2, and to $120 \mu \mathrm{m} \pm 15 \mu \mathrm{m}$ after the addition of both MA2 and US (Fig. 5). There was no difference observed in the grain size of the alloys inoculated with cast and rolled master alloys (MA2) when ultrasonication was applied. Fine $\mathrm{Al}_{3} \mathrm{Zr}$ particles, of $7-12 \mu \mathrm{m}$ in size, were found located within the grains after US processing (Fig. 6). The grain refinement efficiency between MA1 and MA2 was compared for an A357 alloy (Figs. 4 and 7). In the A357 alloy, the initial grain size $(603 \mu \mathrm{m} \pm 120 \mu \mathrm{m})$ was reduced to $460 \mu \mathrm{m} \pm 32 \mu \mathrm{m}$ after an MA1 addition introducing 0.2 wt. $\% \mathrm{Zr}$ (Fig. 7a). With the subsequent application of US, the grain size was further reduced to $190 \mu \mathrm{m} \pm 20 \mu \mathrm{m}$ (Fig. 7b). At the same time, when 0.2 wt. $\% \mathrm{Zr}$ was added by MA2, the grain size was $260 \mu \mathrm{m} \pm 35 \mu \mathrm{m}$, and ultrasonication reduced it

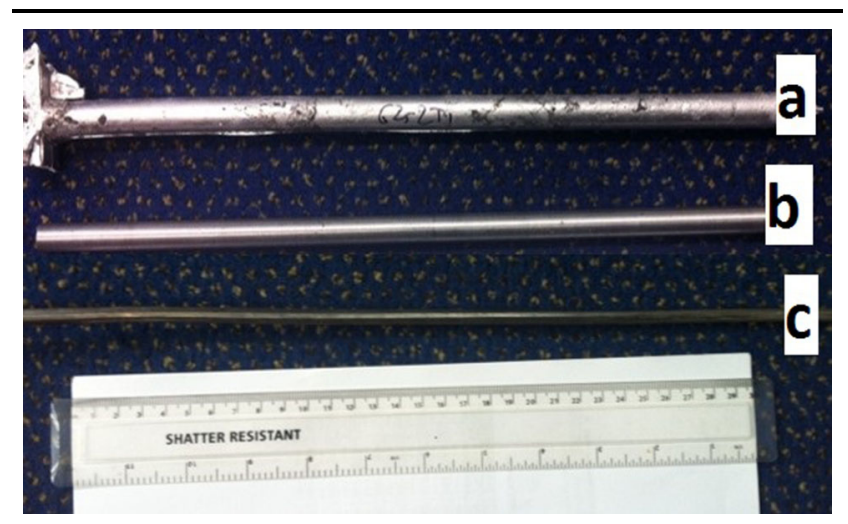

Fig. 1. Cast (a), machined (b) and rolled (c) billets of MA2. 


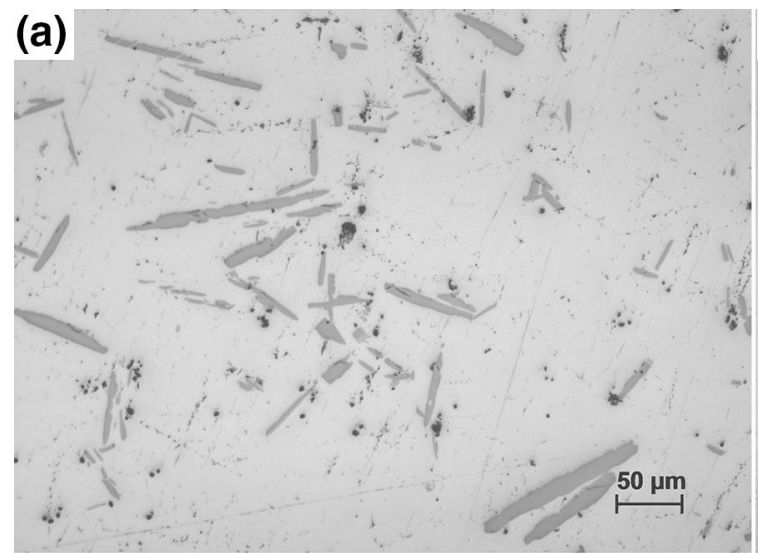

(b)
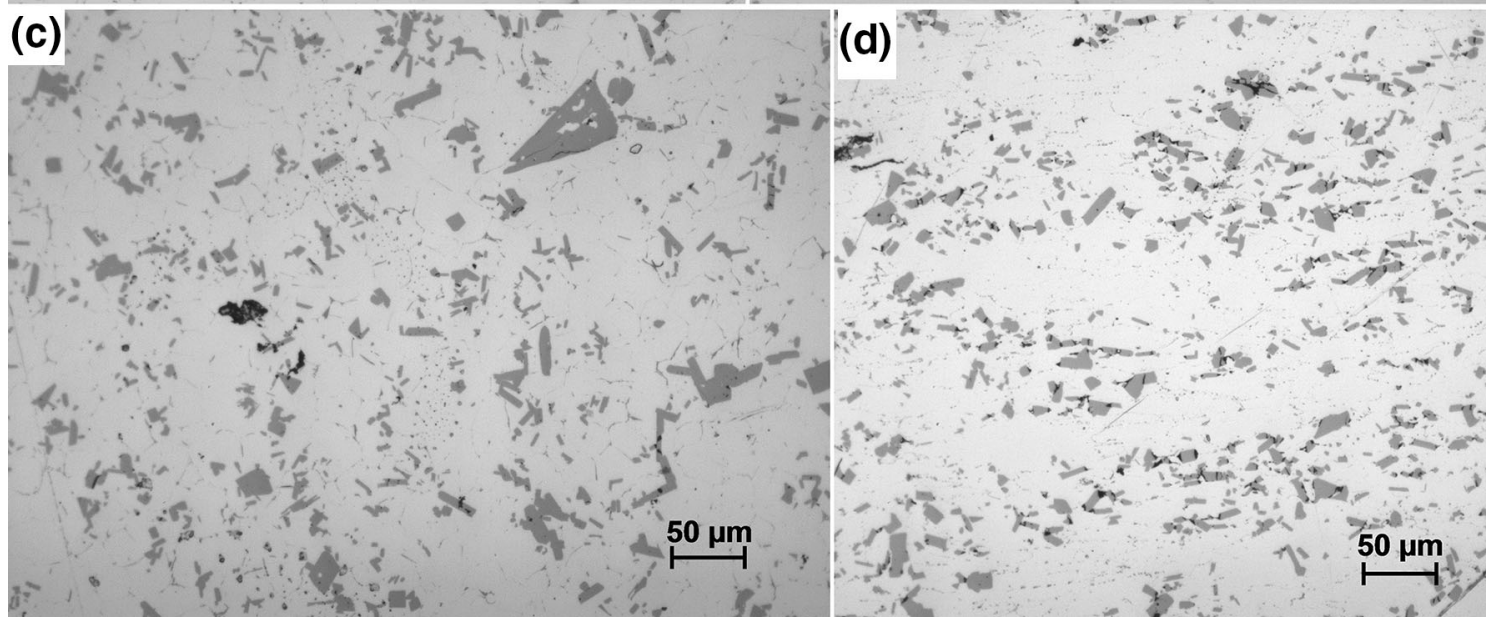

Fig. 2. Microstructures of MA1 (a, b) and MA2 (c, d) after casting (a, c) and rolling (b, d).

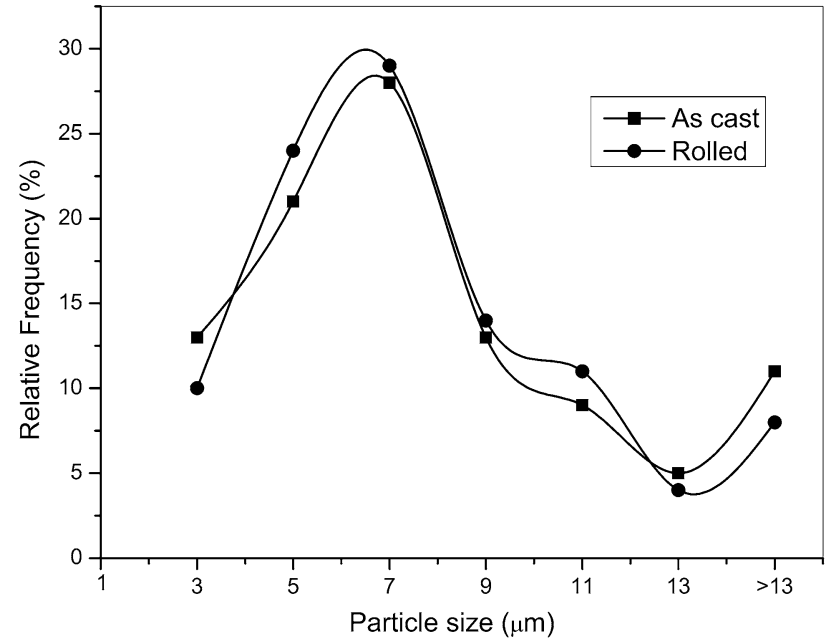

Fig. 3. $\mathrm{Al}_{3} \mathrm{Zr}$ particle size distribution in as-cast and rolled MA2 master alloys.

further to $140 \mu \mathrm{m} \pm 15 \mu \mathrm{m}$ (Fig. 7c). Large dendrites were still present in the A357 alloy inoculated with MA1 and treated with US (Fig. 7b) when

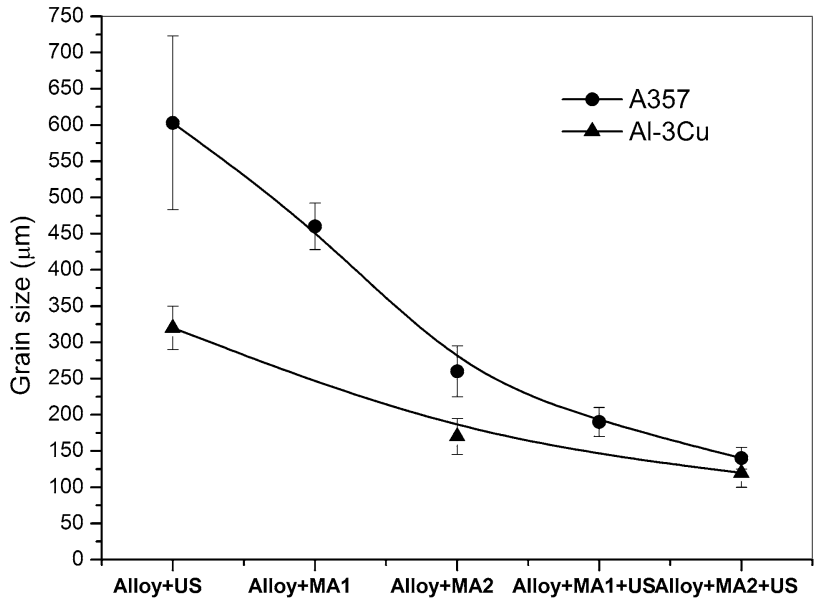

Fig. 4. Grain size distribution in $\mathrm{Al}-3 \mathrm{Cu}$ and $\mathrm{A} 357$ alloys inoculated with either MA1 or MA2 and treated with US as shown on the horizontal axis.

compared with the alloy inoculated with MA2 and treated with US, where more rosette-shaped grains were formed (Fig. 7c). 

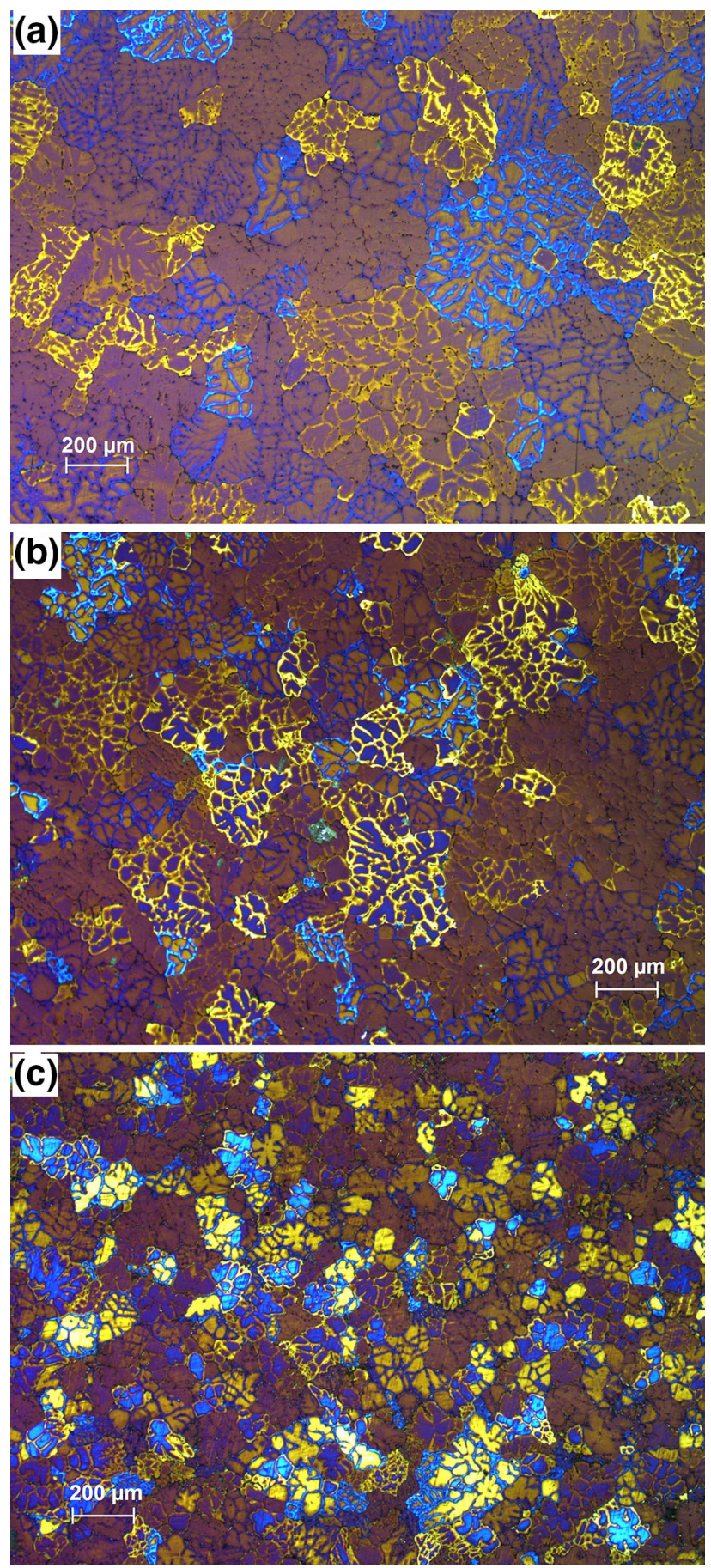

Fig. 5. Anodized microstructure of an Al-3Cu alloy: (a) no MA2, US; (b) MA2, no US; (c) MA2 and US.

\section{DISCUSSION}

The following exothermic reactions would occur in the $\mathrm{Al}-\mathrm{K}_{2} \mathrm{TiF}_{6}-\mathrm{K}_{2} \mathrm{ZrF}_{6}$ mix at $800^{\circ} \mathrm{C}$. $^{11}$

$$
\begin{aligned}
& 13 \mathrm{Al}+3 \mathrm{~K}_{2} \mathrm{TiF}_{6}=3 \mathrm{Al}_{3} \mathrm{Ti}+3 \mathrm{KAlF}_{4}+\mathrm{K}_{3} \mathrm{AlF}_{6} \\
& \Delta G_{1}=-15489.4+12.87 T+0.13 T^{2}-1.9375 \times 10^{5} T^{-1}
\end{aligned}
$$

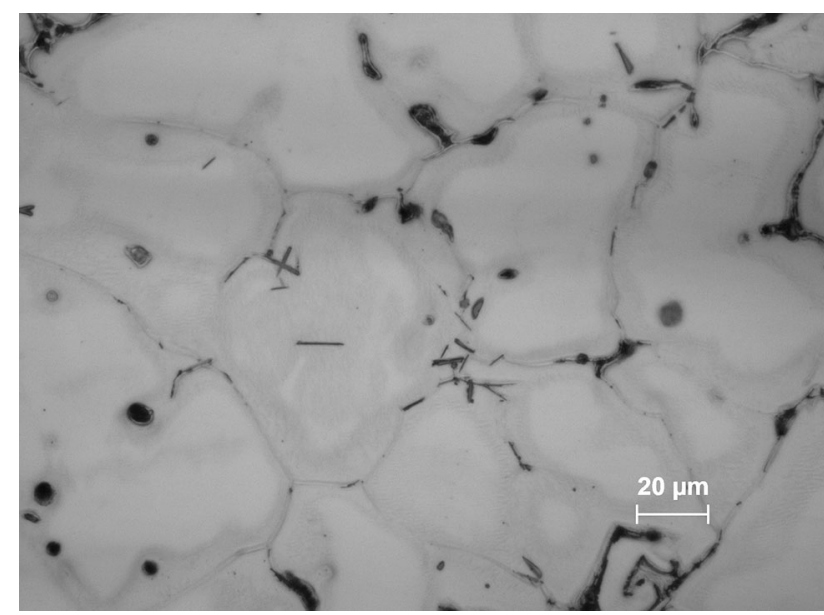

Fig. 6. Microstructure of an $\mathrm{Al}-3 \mathrm{Cu}$ alloy inoculated with MA2 and treated with US (fine $\mathrm{Al}_{3} \mathrm{Zr}$ particles are visible within the grain bulk).

$$
\begin{aligned}
13 \mathrm{Al}+ & 3 \mathrm{~K}_{2} \mathrm{ZrF}_{6}=3 \mathrm{Al}_{3} \mathrm{Zr}+3 \mathrm{KAlF}_{4}+\mathrm{K}_{3} \mathrm{AlF}_{6} \\
\Delta G_{2}= & -179413.2+583.32 T+0.01313 T^{2} \\
& -10.49 \times 10^{5} T^{-1}
\end{aligned}
$$

According to the Al-Zr-Ti phase diagram, Ti has a large solubility in the $\mathrm{Al}_{3} \mathrm{Zr}$ phase forming the $\mathrm{DO}_{23}$ phase $\mathrm{Al}_{3}\left(\mathrm{Zr}_{1-\mathrm{x}} \mathrm{Ti}_{\mathrm{x}}\right)$ up to $x=0.4{ }^{12}$ Hence, reaction (3) would be the most probable at the later stage of the process.

$$
\begin{aligned}
\mathrm{Al}+3 \mathrm{~K}_{2} \mathrm{TiF}_{6}+3 \mathrm{~K}_{2} \mathrm{ZrF}_{6}= & \mathrm{Al}_{3}(\mathrm{Zr}, \mathrm{Ti}) \\
& +6 \mathrm{KAlF}_{4}+2 \mathrm{~K}_{3} \mathrm{AlF}_{6}
\end{aligned}
$$

The $\mathrm{Al}_{3} \mathrm{Zr}$ phase is a sufficiently potent nucleant for aluminum as has been recently confirmed in a thorough study that concluded that the crystallographic matching and the size distribution of $\mathrm{Al}_{3} \mathrm{Zr}$ nucleant particles govern the grain refinement efficiency of this phase. ${ }^{13}$ The reader is referred to Ref. 13 for the details on the crystallography of nucleation in the Al-Zr system.

It was shown that the dissolution of $\mathrm{Ti}$ in $\mathrm{Al}_{3} \mathrm{Zr}$ changes its lattice parameters, which increases the lattice mismatch with $\mathrm{Al}^{14,15}$ The experimental data, ${ }^{9}$ however, showed that the $\mathrm{Ti}$ presence is beneficial for the grain refinement with $\mathrm{Al}_{3} \mathrm{Zr}$ particles. The effect of Ti could be twofold. Firstly, the changes in the lattice parameter may induce internal stresses in the solidifying intermetallic and make its cracking and fragmentation easier under ultrasonic cavitation. Secondly, the free Ti may act as a growth restriction element restricting the growth of $\mathrm{Al}$ grains and providing constitutional undercooling for the nucleation of new grains, just as it does upon addition of a conventional Al-5Ti-1B grain refiner. ${ }^{16}$ So the ultrasonication provides refinement of the primary intermetallics to a critical size at which they can act as seeds for $\mathrm{Al}$ crystals, whereas free Ti restricts the growth of $\mathrm{Al}$ grains and 

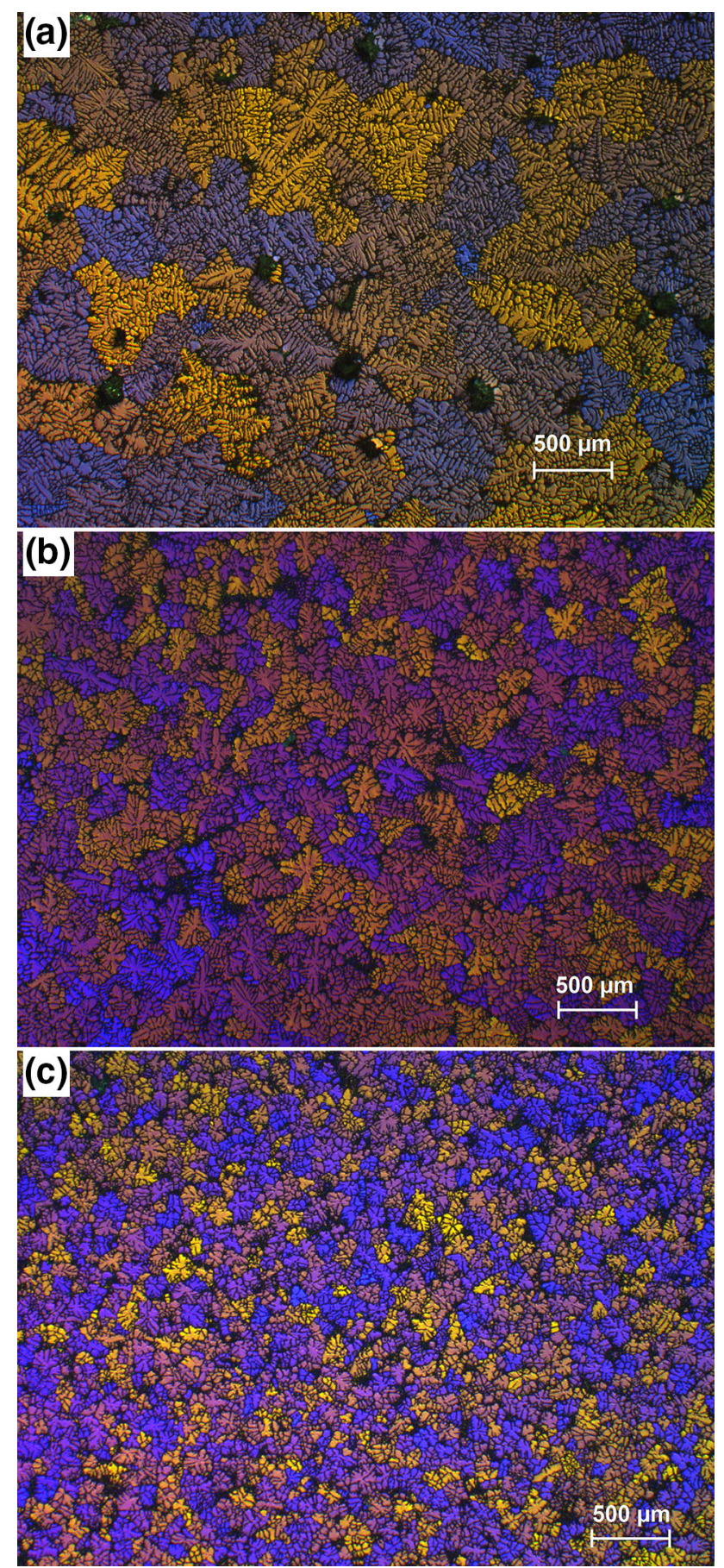

Fig. 7. Microstructure of an A357 alloy: (a) MA1, no US; (b) MA1, US and (c) MA2, US.

promotes (through constitutional undercooling) nucleation of new grains on $\mathrm{Al}_{3} \mathrm{Zr}$ intermetallics. The $\mathrm{Al}_{3} \mathrm{Zr}$ phase is apparently not susceptible to $\mathrm{Si}$ poisoning as this grain refining method works in high-Si alloys with the same efficiency as in wrought alloys.

As was already mentioned, MA1 contained larger $\mathrm{Al}_{3} \mathrm{Zr}$ particles and hot rolling has fragmented only some of these particles, whereas the remaining large $\mathrm{Al}_{3} \mathrm{Zr}$ particles could be fragmented during ultrasonic processing. At the same time, the relatively low melt temperature (between $760^{\circ} \mathrm{C}$ and $700^{\circ} \mathrm{C}$, which is below the liquidus of an $\mathrm{Al}-5 \% \mathrm{Zr}$ alloy) and short US time limit the dissolution of the larger intermetallics rendering them useless for nucleation of $\mathrm{Al}$ (as they supply less solute $\mathrm{Zr}$ into the melt that can later on re-precipitate as fine primary intermetallics). Therefore, the efficiency of MA1 is less than MA2. In the case of MA2, almost $90 \%$ of the particles range between $1 \mu \mathrm{m}$ and $13 \mu \mathrm{m}$ in size and either dissolve to re-form during melt cooling or, if remaining undissolved, act as potential substrates due to their small size. Therefore, MA2 is able to induce significant reduction in the grain size even without ultrasonication. Further grain reduction as a result of US processing is relatively small in both tested alloys. For example, in the A357 alloy, MA2 addition caused a 57\% reduction in grain size and another $20 \%$ after ultrasonication, whereas MA1 addition reduced the grain size by $24 \%$ without ultrasonication and by further $45 \%$ with ultrasonication. Similarly, the grain reduction achieved in the $\mathrm{Al}-3 \mathrm{wt} . \% \mathrm{Cu}$ alloy by sole addition of MA2 is $54 \%$ with only a further $16 \%$ attributed to ultrasonication. A previous grain refinement study on an $\mathrm{Al}-2.5 \mathrm{wt} . \% \mathrm{Cu}$ alloy containing $0.2 \mathrm{wt} . \% \mathrm{Zr}$ added by a commercial master alloy reported a grain size of $280 \mu \mathrm{m}$ without ultrasonication; however, ultrasonication at $700^{\circ} \mathrm{C}$ resulted in significant grain reduction to $58 \mu \mathrm{m} .{ }^{9}$ It can be ascertained from the analysis of previous investigations ${ }^{7,9,15}$ and the present study that ultrasonic treatment results in a much greater reduction in grain size of the alloy inoculated with MA1 type master alloy (or Zr and Ti added separately). But with MA2-type master alloy, where a large volume of fine $\mathrm{Al}_{3} \mathrm{Zr}$ particles are already present, a smaller proportion of the grain refining achieved results from ultrasonication.

\section{CONCLUSION}

A concentrated Al-Zr-Ti master alloy demonstrates good performance as a grain refiner feedstock. This master alloy can be produced by the salt synthesis route and be shaped as rods or billets depending on its usage. The $\mathrm{Al}_{3} \mathrm{Zr}$ particle sizes can be controlled within a few $\mu \mathrm{m}$. The new master alloy produced by in situ salt reaction showed significant grain refinement potential even without ultrasonication. It demonstrated a $30 \%$ improvement in grain refinement efficiency compared to the application of a master alloy produced via a casting route. The master alloy can be used to its full potential with the assistance of ultrasonication in the liquid state (down to the solidification range of primary intermetallics) typically possible in a direct-chill casting or foundry operation. A reduction of up to $80 \%$ in grain size was observed with the equivalent 0.2 wt. $\% \mathrm{Zr}$ master alloy addition combined with ultrasonication of the melt. The alloying elements 
such as $\mathrm{Zr}$ and $\mathrm{Ti}$ are regularly used in commercial $\mathrm{Al}$ alloys and, in addition to the grain refinement, can be useful for recrystallization control.

\section{ACKNOWLEDGEMENTS}

The authors wish to acknowledge financial support from the ExoMet Project, which is co-funded by the European Commission in the 7th Framework Programme (Contract FP7-NMP3-LA-2012-280421), by the European Space Agency and by the individual partner organisations.

\section{OPEN ACCESS}

This article is distributed under the terms of the Creative Commons Attribution 4.0 International License (http://creativecommons.org/licenses/by/4.0/), which permits unrestricted use, distribution, and reproduction in any medium, provided you give appropriate credit to the original author(s) and the source, provide a link to the Creative Commons license, and indicate if changes were made.

\section{REFERENCES}

1. F. Wang, Z. Liu, D. Qiu, J.A. Taylor, M.A. Easton, and M.-X. Zhang, Acta Mater. 61, 360 (2013).

2. G.K. Sigworth and M.M. Guzowski, AFS Trans. 93, 907 (1985).
3. F.A. Crossley and L.F. Mondolfo, Trans. Am. Inst. Min. Metall. Eng. 191, 1143 (1951).

4. L.S. Toropova, D.G. Eskin, T.V. Dobatkina, and M.L. Kharakterova, Advanced Aluminum Alloys Containing Scandium: Structure and Properties (Amsterdam: OPA, 1998).

5. G.I. Eskin, Ultrasonic Treatment of Molten Aluminum, 2nd ed. (Moscow: Metallurgiya, 1988).

6. G.I. Eskin, Ultrasonic Treatment of Light Alloys Melts (Amsterdam: OPA, 1998).

7. L. Zhang, D.G. Eskin, and L. Katgerman, J. Mater. Sci. 46, $5252(2011)$.

8. G.I. Eskin, Ultrasonic Treatment of Molten Aluminum, 1st ed. (Moscow: Metallurgiya, 1965).

9. T.V. Atamanenko, D.G. Eskin, L. Zhang, and L. Katgerman, Metall. Mater. Trans. 41A, 2056 (2010).

10. F. Wang, D. Eskin, J. Mi, T. Connolley, J. Lindsay, and M. Mounib, Acta Mater. 116, 354 (2016).

11. X. Zhang, G. Li, T. Zhang, L. Cao, H. Wang, J.J. Wang, K. $\mathrm{Gu}, \mathrm{H}$. Zhang, and X.J. Xu, Appl. Mech. Mater. 217-219, 114 (2012).

12. L. Tretyachenko, Ternary Alloy Systems, Sub volume A, Part 4 (Berlin: Springer/MSI, 2006), pp. 54-67.

13. F. Wang, D. Qiu, Z.-L. Liu, J.A. Taylor, M.A. Easton, and M.-X. Zhang, Acta Mater. 61, 5636 (2013).

14. M. Zedalis and M.E. Fine, Scrip. Metall. 17, 1247 (1983).

15. T.V. Atamanenko, D.G. Eskin, M. Sluiter, and L. Katgerman, J. Alloys Comp. 509, 57 (2011).

16. M. Easton and D. StJohn, Metall. Mater. Trans. A 30A, 1625 (1999). 